\title{
Effects of Thermal Radiation, Heat Generation, and Induced Magnetic Field on Hydromagnetic Free Convection Flow of Couple Stress Fluid in an Isoflux-Isothermal Vertical Channel
}

\author{
Hasan Nihal Zaidi $(\mathbb{D}$, Mohammed Yousif, and S. Nazia Nasreen \\ Department of Basic Sciences, College of Preparatory Year, University of Hail, Saudi Arabia \\ Correspondence should be addressed to Hasan Nihal Zaidi; hasannihalzaidi@hotmail.com
}

Received 16 March 2020; Revised 20 July 2020; Accepted 17 August 2020; Published 7 September 2020

Academic Editor: Sazzad Hossien Chowdhury

Copyright (c) 2020 Hasan Nihal Zaidi et al. This is an open access article distributed under the Creative Commons Attribution License, which permits unrestricted use, distribution, and reproduction in any medium, provided the original work is properly cited.

\begin{abstract}
The study scrutinizes the effects of thermal radiation, heat generation, and induced magnetic field on steady, fully developed hydromagnetic free convection flow of an incompressible viscous and electrically conducting couple stress fluid in a vertical channel. The channel walls are maintained at an isoflux-isothermal condition, such that the left channel wall is maintained at a constant heat flux. In contrast, the right channel wall is maintained at a constant temperature. The governing simultaneous equations are solved analytically utilizing the method of undetermined coefficient, and closed form solutions in dimensionless form have been acquired for the velocity field, the induced magnetic field, and the temperature field. The expression for the induced current density has been also obtained. A parametric study for the velocity, temperature, and induced magnetic field profiles, as well as for the skin-friction coefficient, Nusselt number, and induced current density, is conducted and discussed graphically.
\end{abstract}

\section{Introduction}

The problem of hydromagnetic free convection and heat transfer flow through a vertical channel has drawn much attention due to its possible application in many engineering and technological activities. A magnetic field induced to the fluid flow generates an electromotive force and changes the velocity distribution. The behavior of flow firmly relies upon the orientation and strength of the applied magnetic field. The applied magnetic field manipulates the suspended particles and modifies their concentration in the fluid, which unequivocally changes heat transfer characteristics of the flow. Such flows are found in the fusion reactors, MHD generator, MHD pumps, MHD bearings, etc. The effect of a magnetic field on free convection heat transfer was discussed by Sparrow and Cess [1]. They investigated the simultaneous action of buoyancy and induced magnetic field on free convection heat transfer. In the presence of electrical or magnetic fields, Poots [2] considered the natural convection flow of an electrically conducting viscous fluid, such as mercury or liquid sodium. He examined natural convection flow between two long parallel plane surfaces with a uniform magnetic field applied normal to the surfaces, with and without heat sources, and natural convection flow through a horizontal circular tube. Ghosh et al. [3] have investigated hydromagnetic natural convection boundary layer flow in the presence of an induced magnetic field on an infinite vertical plate and obtained an exact solution. Singh et al. [4] numerically studied free convection flow in a vertical channel under the influence of an applied magnetic field, including the effect of magnetic induction. Magnetohydrodynamic free convection flow between two vertical parallel porous plates was analyzed by Sarvesanand and Singh [5] considering the effect of the induced magnetic field emanating from the motion of an electrically conducting fluid. MHD convection fluid flow and heat transfer in an inclined microchannel with heat 
generation were studied by Zaidi and Ahmad [6]. Kumar and Singh [7] have discussed unsteady MHD free convection flow past a semi-infinite vertical wall with the induced magnetic field and solved coupled nonlinear partial differential equations by the Crank-Nicolson, finite difference method. Jha and Aina $[8,9]$ analyzed magnetohydrodynamic natural convection flow in a vertical porous or nonporous microchannel in the presence of an induced magnetic field. Recently, Mohammad et al. [10] investigated magnetohydrodynamic- (MHD-) radiated nanomaterial viscous material flow through a curved surface with second-order slip and entropy generation considering the effects of viscous dissipation, thermal radiation, and Joule heating. In the modeling of flow problem, they utilized the Buongiorno model thermophoresis and Brownian diffusion.

The thermal radiation effect on the free convection flow is important in the context of space technology and many engineering applications, such as in advanced types of power plants for nuclear rockets, reentry vehicles, high-speed flights, and procedures involving high temperatures. The Rosseland diffusion approximation is valid for optically thick media. The radiative heat fluxes approximated for an optically dense medium by the Rosseland diffusion approximation have been used extensively in many studies related to radiation. Cess [11] examined the effect of radiation on boundary-layer development in free convection of an absorbing-emitting gas on a vertical plate, and he presented interactions between radiation and free convection. The combined radiative and convective heat transfer in a vertical channel has been studied by Bouali and Mezrhab [12] and Grosan and Pop [13]. Kaladhar et al. [14] have presented mixed convection flow of couple stress fluid in a vertical channel with radiation and Soret effect employing a quasilinearization method. The entropy generation in the flow of ferromagnetic nanofluid with nonlinear radiation and slip condition on a nonlinear stretching sheet is explored by Rashid et al. [15]. Recently, Gireesha et al. [16] have studied the impact of thermal radiation and natural convection on nanoparticle-embedded water-based hybrid nanofluid flow across a permeable longitudinal fin using Darcy's model.

Studies related to the free convection channel flow and heat transfer characteristic of couple stress fluids find several applications in many industrial processes such as the extrusion of polymer fluids, solidification of liquid crystals, and cooling of metallic plates in bath colloidal solution. To describe the flow of microcontinuum fluids (complex fluids), various general theories as well as specific methods were developed from time to time. The key feature of couple stresses is the implementation of a size-dependent effect. The size effect of material particles within the continua is neglected by classical continuum mechanics. This is consistent with ignoring the rotational interaction between the fluid particles, which results in symmetry of the force-stress tensor. Nevertheless, this cannot be valid in some important cases such as fluid flow with suspended particles, and a sizedependent couple stress theory is required. Stokes $[17,18]$ introduced the theory of couple stress fluids. He presented the straightforward generalization of the classical theory that allows polar effects such as the presence of couple stresses and body couples. The couple stress fluids also have the mechanism to describe rheological complex fluid-like liquid crystal and human blood. The rheological properties of such fluids are important in the flow of nuclear fuel slurries, lubricants with heavy oil and greases, paper coating, and polymers. Soundalgekar and Aranake [19] analyzed the fully developed MHD couple stress fluid in a channel and observed that the couple stresses are more effective in the presence of a weak magnetic field. Free convection of a couple stress fluid in a vertical channel was considered by Umavathi et al. [20]. Kaladhar [21] has obtained a solution using a homotopy analysis method for the natural convection of a couple stress fluids between two vertical plates, taking into account the Hall and Joule heating effects. Numerically, Makinde and Eegunjobi [22] contemplated the combined effects of nonlinear thermal radiation, buoyancy forces, thermophoresis, and Brownian motion on the entropy generation rate in hydromagnetic couple stress nanofluid flow through a vertical channel utilizing a shooting technique combined with the Runge-Kutta-Fehlberg method.

To the best of the authors' knowledge, the effects of thermal radiation, heat generation, and an induced magnetic field on hydromagnetic free convection flow of couple stress fluid in an isoflux-isothermal vertical channel have not been reported in the literature. The governing equations for the velocity field, induced magnetic field, and temperature field were solved analytically. A parametric study was conducted, and the results were portrayed and discussed with the help of graphs.

\section{Mathematical Formulation}

Consider a laminar free convection flow of an electrically conducting couple stress fluid in a vertical parallel plate channel separated by a distance $h$. The walls of the channel were maintained at the isoflux-isothermal condition. The physical configuration of the problem is shown in Figure 1. We choose a Cartesian coordinate system such that the $x^{\prime}$-axis is taken vertically upward along the plates and the $y^{\prime}$-axis is normal to the channel. A uniform magnetic field of strength $B_{0}^{\prime}$ is imposed in the direction normal to the flow direction. For a fluid with significant electrical conductivity $\sigma_{e}$, this in turn induces a magnetic field $B_{x}^{\prime}$ along the $x^{\prime}$-axis. Let $u^{\prime}$ be the velocity of the fluid along the $x^{\prime}$-axis, then the velocity $\left(u^{\prime}\left(\mathrm{y}^{\prime}\right), 0,0\right)$ has only a vertical component and is a function of $y^{\prime}$ only. In contrast, magnetic field $\left(B_{x}^{\prime}, B_{0}^{\prime}, 0\right)$ has a component in the $x^{\prime}$ - and $y^{\prime}$-directions, respectively. The following assumptions are adopted to facilitate the solution of the governing equations.

(1) The flow is steady and fully developed

(2) The fluid physical properties are constant, except the density in the body force term in the momentum equation for which the Boussinesq approximation is invoked

(3) The flux of thermal radiation in the $y$-direction is negligible compared to the $x$-direction 


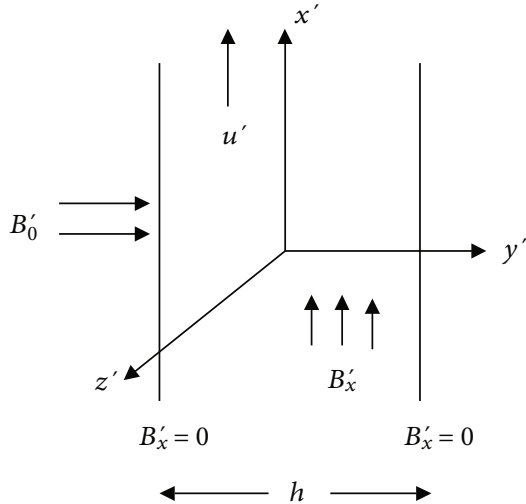

Figure 1: Physical configuration and coordinate system.

Under these assumptions, the governing equations of the system are $[7-9,22]$

$$
\begin{gathered}
v \frac{d^{2} u^{\prime}}{d y^{\prime 2}}-\left(\frac{\eta}{\rho}\right) \frac{d^{4} u^{\prime}}{d y^{\prime 4}}+\left(\frac{\mu_{e} B_{0}^{\prime}}{\rho}\right) \frac{d B_{x}^{\prime}}{d y^{\prime}}+g \beta\left(T-T_{0}\right)=0, \\
\left(\frac{1}{\sigma_{e} \mu_{e}}\right) \frac{d^{2} B_{x}^{\prime}}{d y^{\prime 2}}+B_{0}^{\prime} \frac{d u^{\prime}}{d y^{\prime}}=0, \\
\left(\frac{k}{\rho c_{p}}\right) \frac{d^{2} T}{d y^{\prime 2}}+\frac{Q_{0}}{\rho c_{p}}\left(T-T_{0}\right)-\frac{d q_{r}}{d y^{\prime}}=0 .
\end{gathered}
$$

Using the Rosseland approximation, the radiative heat flux $q_{r}$ is given by

$$
q_{r}=-\frac{4 \sigma^{*}}{3 k^{*}} \frac{\partial T^{4}}{\partial y},
$$

where $\sigma^{*}$ and $k^{*}$ are the Stefan Boltzmann constant and Rosseland mean absorption coefficient, respectively. Consider that the temperature difference within the flow is sufficiently small such that $T^{4}$ may be expressed as a linear function of temperature.

$$
T^{4} \approx 4 T_{h}^{3} T-3 T_{h}^{4} .
$$

Using Equations (4) and (5), Equation (3) becomes

$$
\left(\frac{k}{\rho c_{p}}+\frac{16 \sigma^{*} T_{h}^{3}}{3 k^{*}}\right) \frac{d^{2} T}{d y^{\prime 2}}+\frac{Q_{0}}{\rho c_{p}}\left(T-T_{0}\right)=0 .
$$

The associated boundary conditions are

$$
\begin{aligned}
& u^{\prime}=0, \frac{d^{2} u^{\prime}}{d y^{\prime 2}}=0, B_{x}^{\prime}=0, q_{1}=-k\left(\frac{d T}{d y^{\prime}}\right) \text { at } y^{\prime}=0, \\
& u^{\prime}=0, \frac{d^{2} u^{\prime}}{d y^{\prime 2}}=0, B_{x}^{\prime}=0, T=T_{2} \text { at } y^{\prime}=h .
\end{aligned}
$$

Introducing dimensionless parameters

$$
\begin{aligned}
u & =\frac{u^{\prime}}{u_{0}}, y=\frac{y^{\prime}}{h}, \theta=\frac{T-T_{0}}{\Delta T}, M=\frac{B_{0}^{\prime} h}{v} \sqrt{\frac{\mu_{e}}{\rho}}, B=\frac{B_{x}^{\prime}}{u_{0}} \sqrt{\frac{\mu_{e}}{\rho}}, \text { Rt } \\
& =\frac{T_{2}-T_{1}}{\Delta T}, u_{0}=\frac{g \beta \Delta T h^{2}}{\mu} .
\end{aligned}
$$

Equations (1), (2), and (6) become

$$
\begin{gathered}
\sigma^{2} \frac{d^{4} u}{d y^{4}}-\frac{d^{2} u}{d y^{2}}-M \frac{d B}{d y}-\theta=0, \\
\frac{d^{2} B}{d y^{2}}+M \operatorname{Pm} \frac{d u}{d y}=0, \\
\left(1+\frac{4 R}{3}\right) \frac{d^{2} \theta}{d y^{2}}+\phi \theta=0,
\end{gathered}
$$

where $R=16 \sigma^{*} T_{h}^{3} / 3 k^{*}$ is the radiation parameter, $\sigma=$ $(1 / h) \sqrt{\eta / \mu}$ is the couple stress parameter, $\phi=Q_{0} h^{2} / k$ is heat generation coefficient, and $\mathrm{Pm}=\nu \sigma \mu_{e}$ is the magnetic Prandtl number.

The relevant dimensionless boundary conditions are

$$
\begin{aligned}
& u=0, \frac{d^{2} u}{d y^{2}}=0, B=0, \frac{d \theta}{d y}=-1 \text { at } y=0, \\
& u=0, \frac{d^{2} u}{d y^{2}}=0, B=0, \theta=\text { Rt at } y=1 .
\end{aligned}
$$

Solutions of Equations (9)-(11) are subjected to the boundary conditions (12a) and (12b) given by

$$
\theta=c_{1} \sin \left(a_{1} y\right)+c_{2} \cos \left(a_{1} y\right),
$$

$$
\begin{aligned}
u= & c_{3}+c_{4} \cosh \left(a_{2} y\right)+c_{5} \sinh \left(a_{2} y\right)+c_{6} \cosh \left(a_{3} y\right) \\
& +c_{7} \sinh \left(a_{3} y\right)+\left(\frac{1}{a_{4}}\right)\left\{c_{1} \sin \left(a_{1} y\right)+c_{2} \cos \left(a_{1} y\right)\right\}
\end{aligned}
$$

$$
\begin{aligned}
B= & c_{8}-(M \operatorname{Pm})\left\{\left(\frac{c_{4}}{a_{2}}\right) \sinh \left(a_{2} y\right)+\left(\frac{c_{5}}{a_{2}}\right) \cosh \left(a_{2} y\right)\right. \\
& \left.+\left(\frac{c_{6}}{a_{3}}\right) \sinh \left(a_{3} y\right)+\left(\frac{c_{7}}{a_{3}}\right) \cosh \left(a_{3} y\right)\right\} \\
& +\left(\frac{M P m}{a_{1} a_{4}}\right)\left\{c_{1} \sin \left(a_{1} y\right)+c_{2} \cos \left(a_{1} y\right)\right\},
\end{aligned}
$$




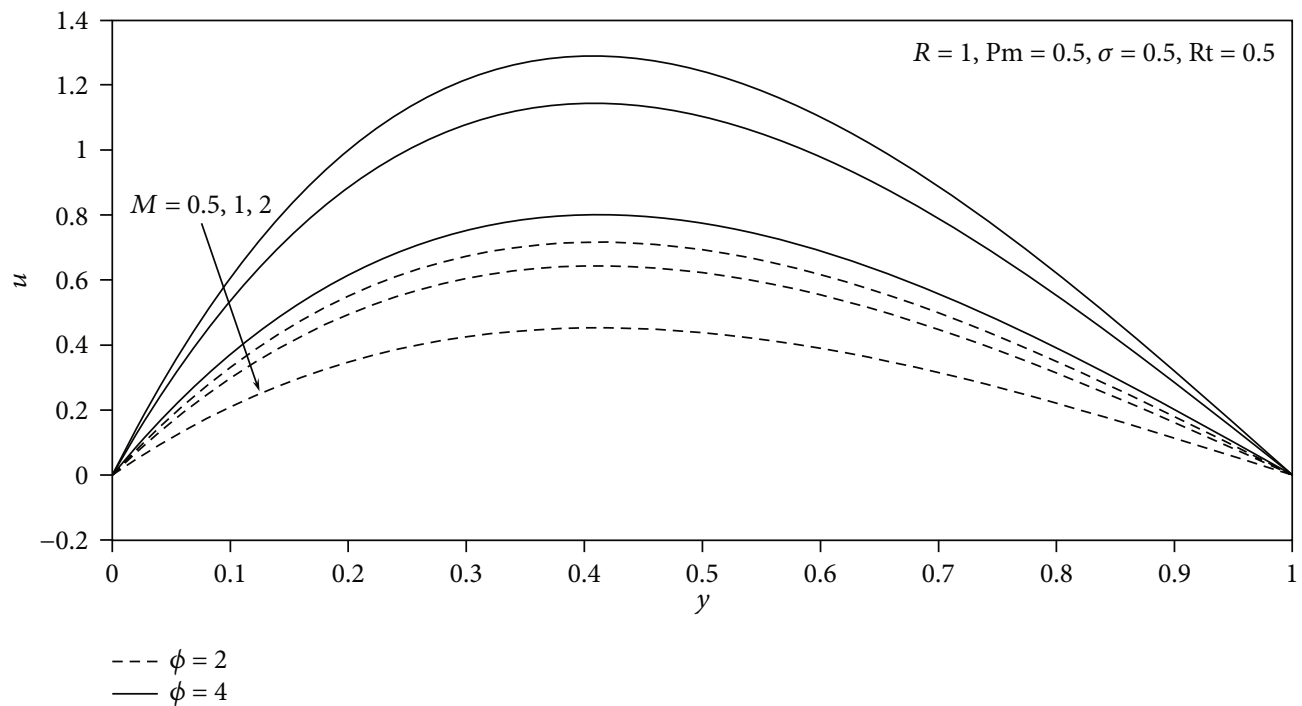

Figure 2: Velocity profiles for different values of $M$ and $\phi$.

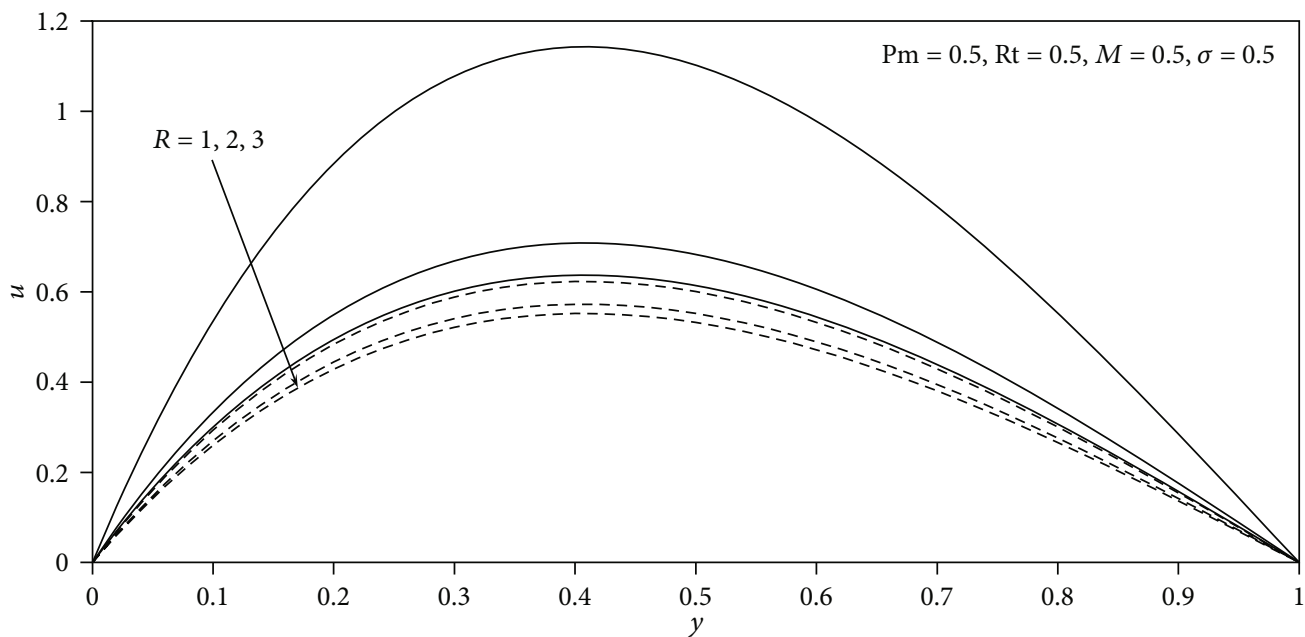

$---\phi=2.0$

$-\phi=4.0$

Figure 3: Velocity profiles for different values of $R$ and $\phi$.

The induced current density is given by

$$
\begin{aligned}
J= & -\frac{d B}{d y}=\operatorname{MPm}\left\{c_{4} \cosh \left(a_{2} y\right)+c_{5} \sinh \left(a_{2} y\right)+c_{6} \cosh \left(a_{3} y\right)\right. \\
& \left.+c_{7} \sinh \left(a_{3} y\right)\right\}+\left(\frac{M P \mathrm{Pm}}{a_{4}}\right)\left\{c_{1} \sin \left(a_{1} y\right)+c_{2} \cos \left(a_{1} y\right)\right\}
\end{aligned}
$$

where $a_{1}, a_{2}, a_{3}, a_{4}, c_{1}, c_{2}, c_{3}, c_{4}, c_{5}, c_{6}, c_{7}$, and $c_{8}$ are constants and are given in the appendix.
The skin friction on both channel walls in dimensionless form is

$$
s_{0}=\left(\frac{d u}{d y}\right)_{y=0}=c_{5} a_{2}+c_{7} a_{3}+c_{1} a_{1} a_{4} \text {, }
$$

$$
\begin{aligned}
s_{1}= & \left(\frac{d u}{d y}\right)_{y=1}=c_{4} a_{2} \sinh \left(a_{2}\right)+c_{5} a_{2} \cosh \left(a_{2}\right)+c_{6} a_{3} \sinh \left(a_{3}\right) \\
& +c_{7} a_{3} \cosh \left(a_{3}\right)+a_{1} a_{4}\left\{c_{1} \cos \left(a_{1}\right)-c_{2} \sin \left(a_{1}\right)\right\} .
\end{aligned}
$$




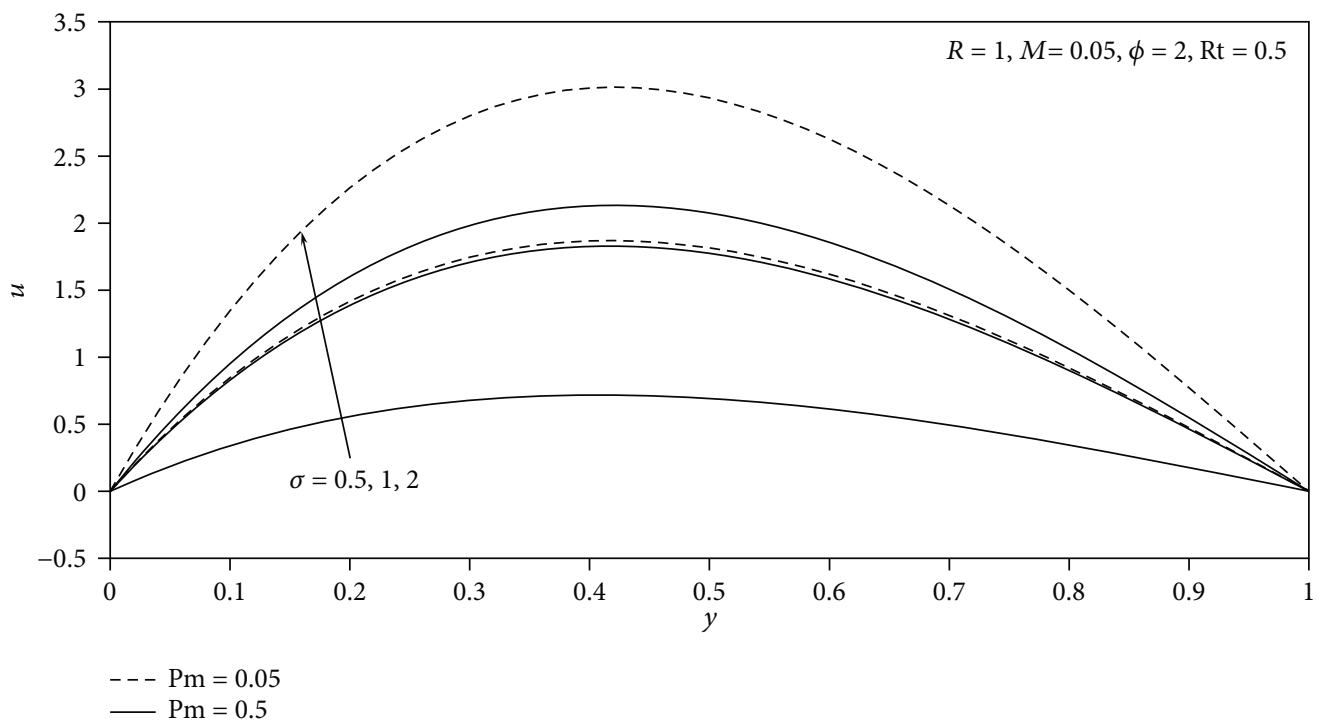

Figure 4: Velocity profile for different values of $\sigma$ and Pm.

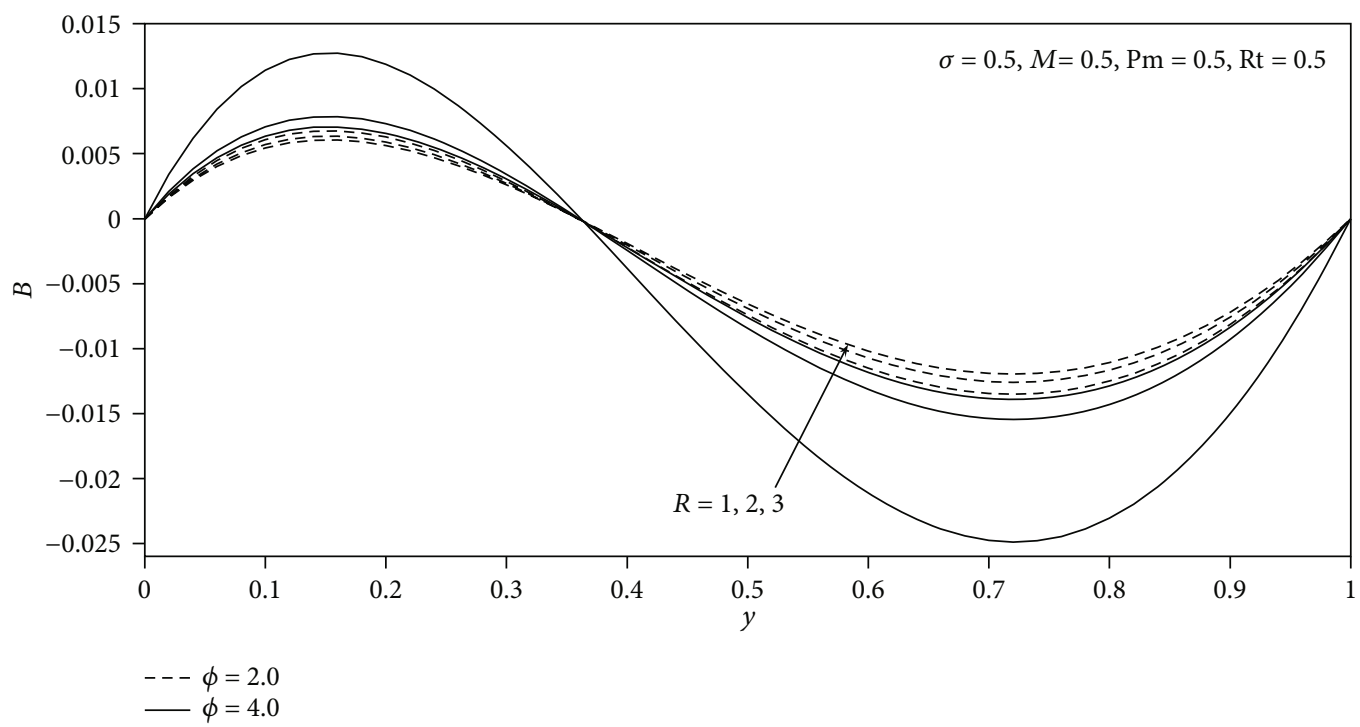

FIgURE 5: Induced magnetic field for different values of $\phi$ and $R$.

And the Nusselt number $(\mathrm{Nu})$ in dimensionless form is

$$
\begin{aligned}
& \mathrm{Nu}_{0}=-\left(\frac{d \theta}{d y}\right)_{y=0}=c_{1} a_{1}=-1, \\
& \mathrm{Nu}_{1}=-\left(\frac{d \theta}{d y}\right)_{y=1}=-a_{1}\left\{c_{1} \cos \left(a_{1}\right)-c_{2} \sin \left(a_{1}\right)\right\} .
\end{aligned}
$$

\section{Results and Discussion}

In the present study, the effect of thermal radiation, heat generation, and an induced magnetic field on hydromagnetic free convection flow of couple stress fluid in an isofluxisothermal vertical channel is analyzed. The governing equa- tions solved analytically, the obtained closed form solution for Equations (9)-(11), and the computed results of the analytical solutions are presented in Figures 2-17.

Figure 2 shows the variation of velocity for different values of Hartmann number $M$ and the heat generation coefficient $\phi$. It is clear that the velocity of fluid particles decreases on the increase of the Hartmann number $M$ because as the magnetic field intensity increases, the resisting Lorentz force will increase; consequently, the velocity profile decreases. Meanwhile, in the same figure, a rise in heat generation coefficient $\phi$ enhances the velocity profile. Figure 3 illustrates the effect of the radiation parameter $R$ on the velocity profile. The velocity of fluid particles decreases with the increase in radiation parameter $R$. The maximum velocity occurs at $y=0.4$ for $R=1$, and it shifts towards the wall $y=0.0$. The effect of the magnetic Prandtl number Pm and the couple stress 


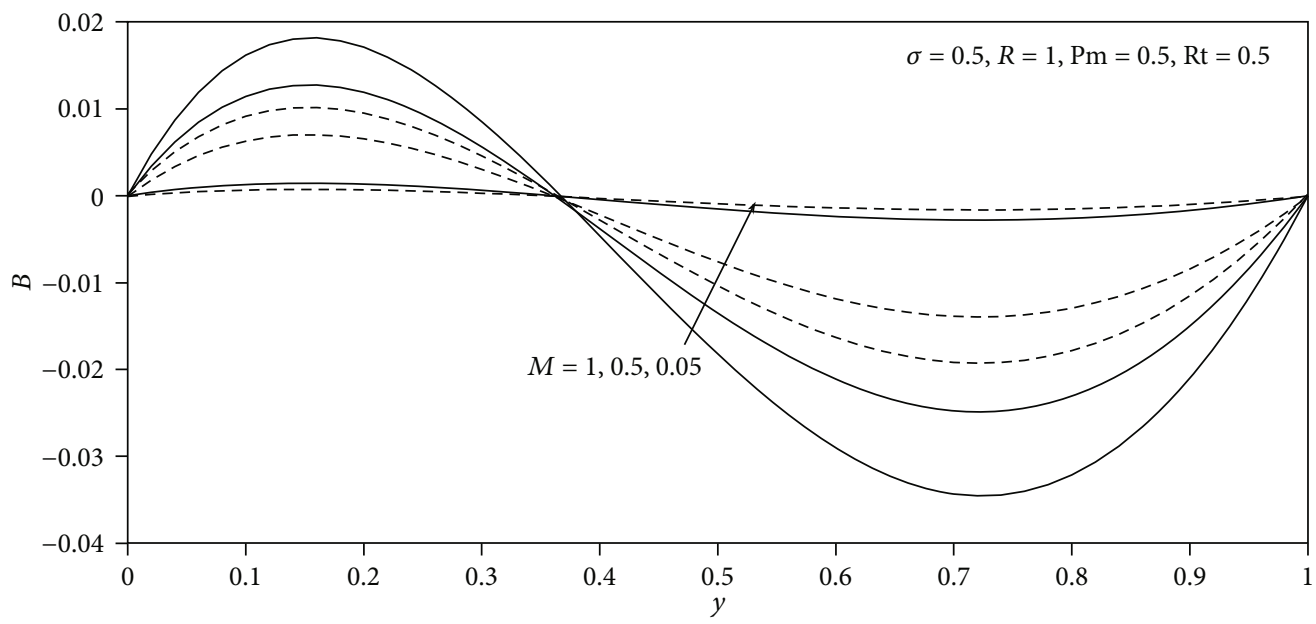

$--\phi=2.0$

$-\phi=4.0$

Figure 6: Induced magnetic field for different values of $M$ and $\phi$.

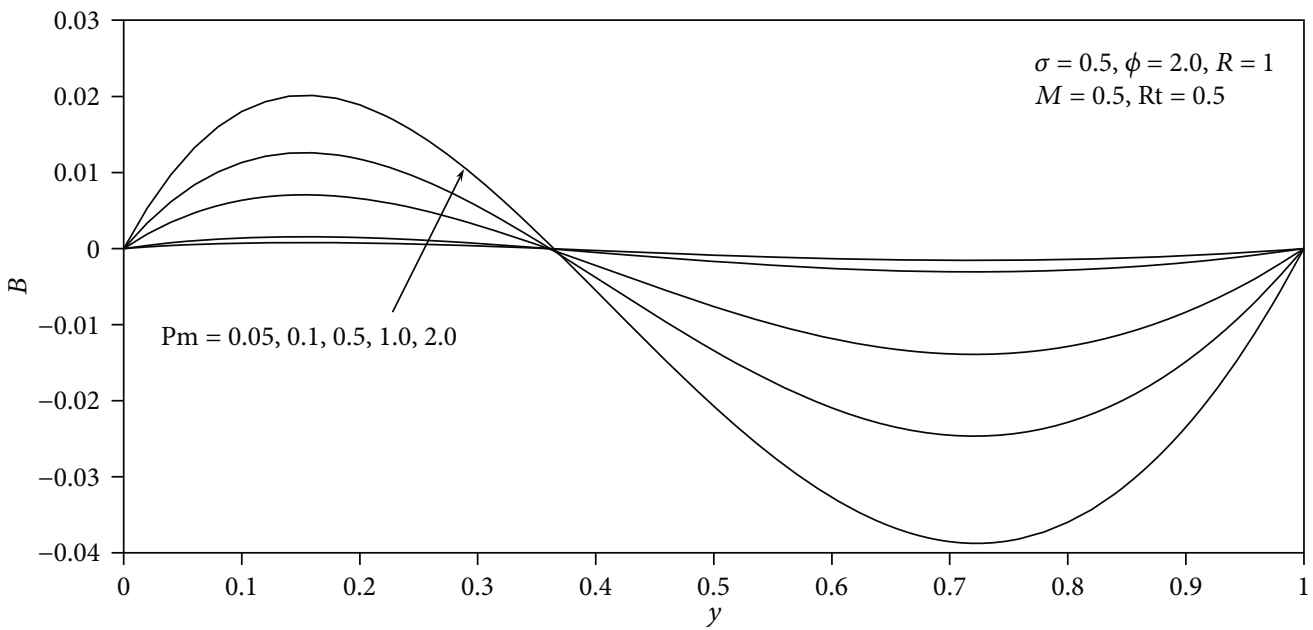

Figure 7: Induced magnetic field for different values of the magnetic Prandtl number Pm.

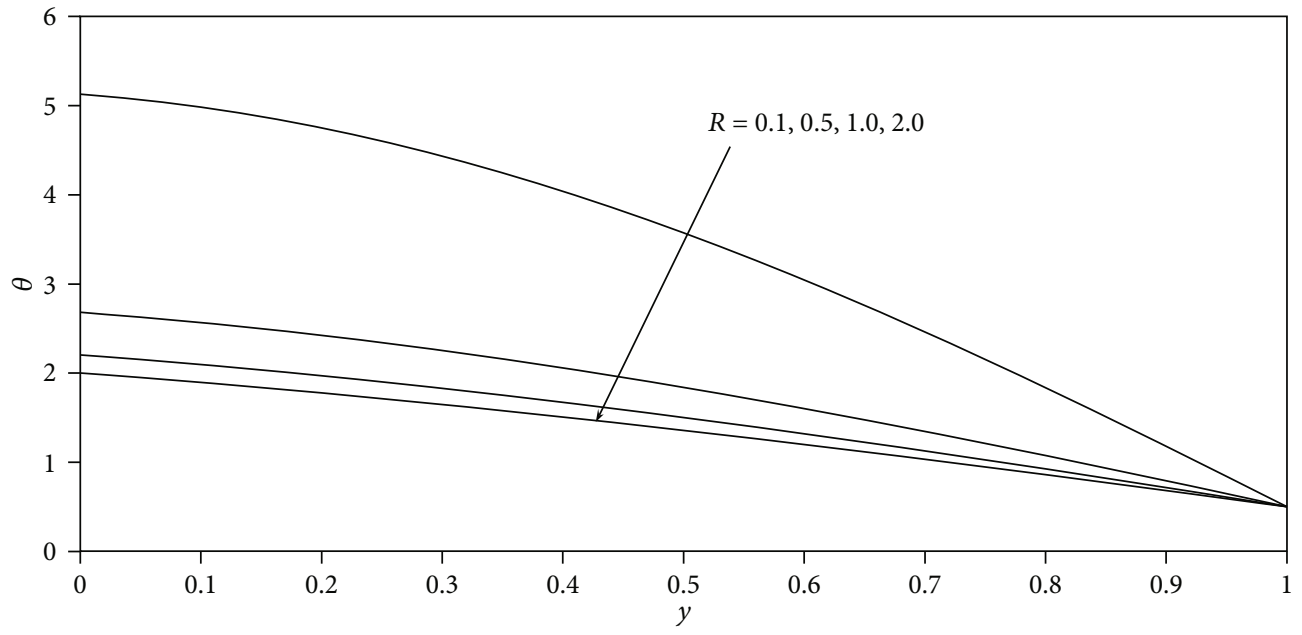

Figure 8: Temperature profiles for different values of $R$ at $\phi=2.0$. 


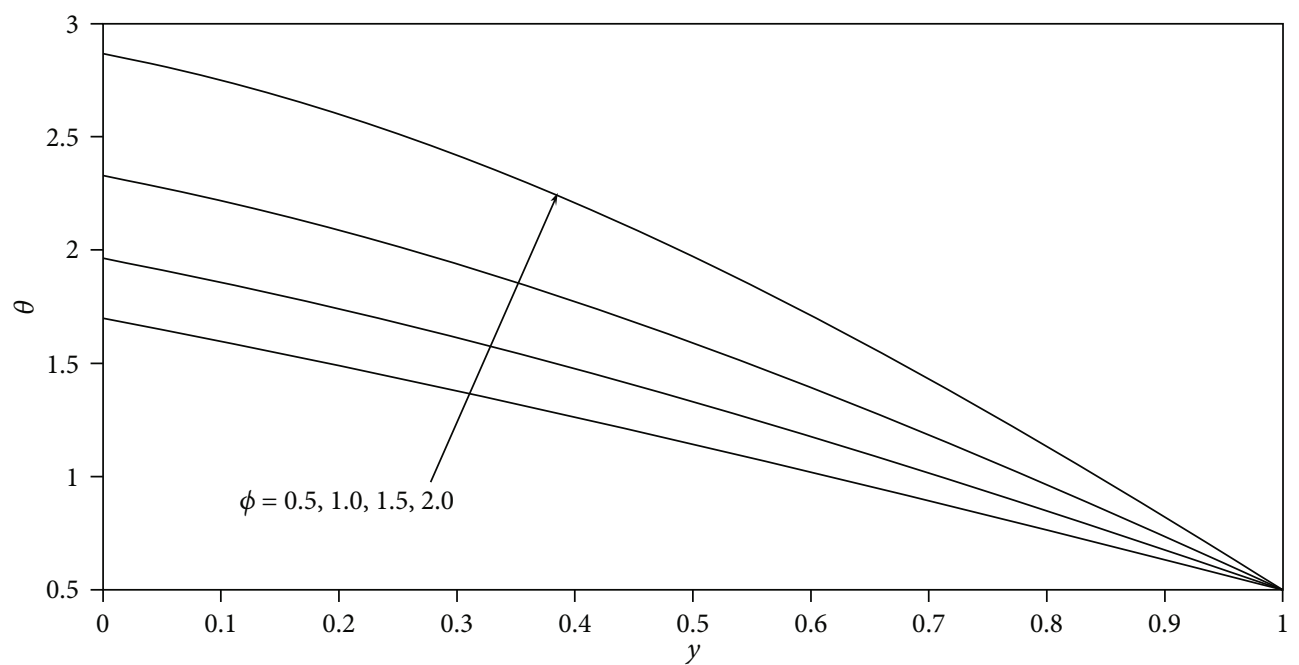

FIGURE 9: Temperature profiles for different values of $\phi$ at $R=0.5$.

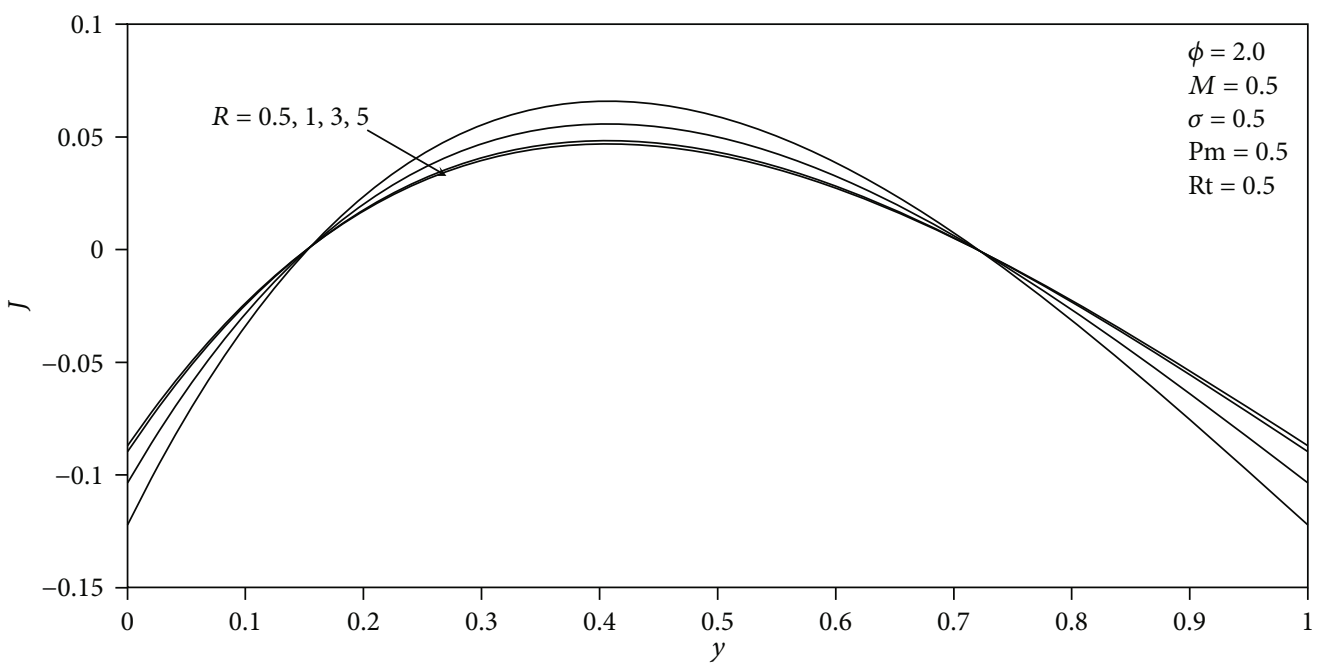

Figure 10: Induced current density for different values of radiation parameter $R$.

parameter $\sigma$ on the velocity profile is displayed in Figure 4. It is evident from Figure 4 that an increase in the value of the couple stress parameter $\sigma$ enhances the velocity of fluid particles while the velocity of the fluid particles decreases with increase of the magnetic Prandtl number Pm. It can also be noted that when $\sigma \rightarrow 0$, the velocity becomes large; this shows that the velocity in the case of couple stress fluid is less than that in the Newtonian fluid case.

Figures 5-7 describe the behavior of the induced magnetic field with the various parameters. Figure 5 shows the effect of radiation parameter $R$ and heat generation coefficient $\phi$ on the induced magnetic field profile. It is observed that in the first one-third of the channel, as the value of radiation parameterRincreases, the induced magnetic field decreases and the reverse is the case in the remaining part of the channel; conversely, as the value of $\phi$ increases, the induced magnetic field increases from $y=0.0$ to $y=0.4$ and reverses its direction from $y=0.4$ to $y=1.0$. Figures 6 and 7 display the effect of the Hartmann number $M$ and the magnetic Prandtl number Pm on the induced magnetic field, respectively. It is noted that the induced magnetic field is directly proportional to the Hartmann number as well as the magnetic Prandtl number near the channel wall at $y=0.0$ while it is inversely proportional near the channel wall at $y=1.0$.

The effect of radiation parameter $R$ and heat generation coefficient $\phi$ on the temperature profile is illustrated in Figures 8 and 9 , respectively. It was found that temperature decreases with the increase of the radiation parameter; meanwhile, a rise in the heat generation coefficient increases the temperature of the fluid.

Figures 10-12 depicts the behavior of induced current density with the various parameters occurring in the governing equations. Figure 10 exhibits the variation of induced current density concerning radiation parameter $R$. It is clear from the graph that the value of induced current density 


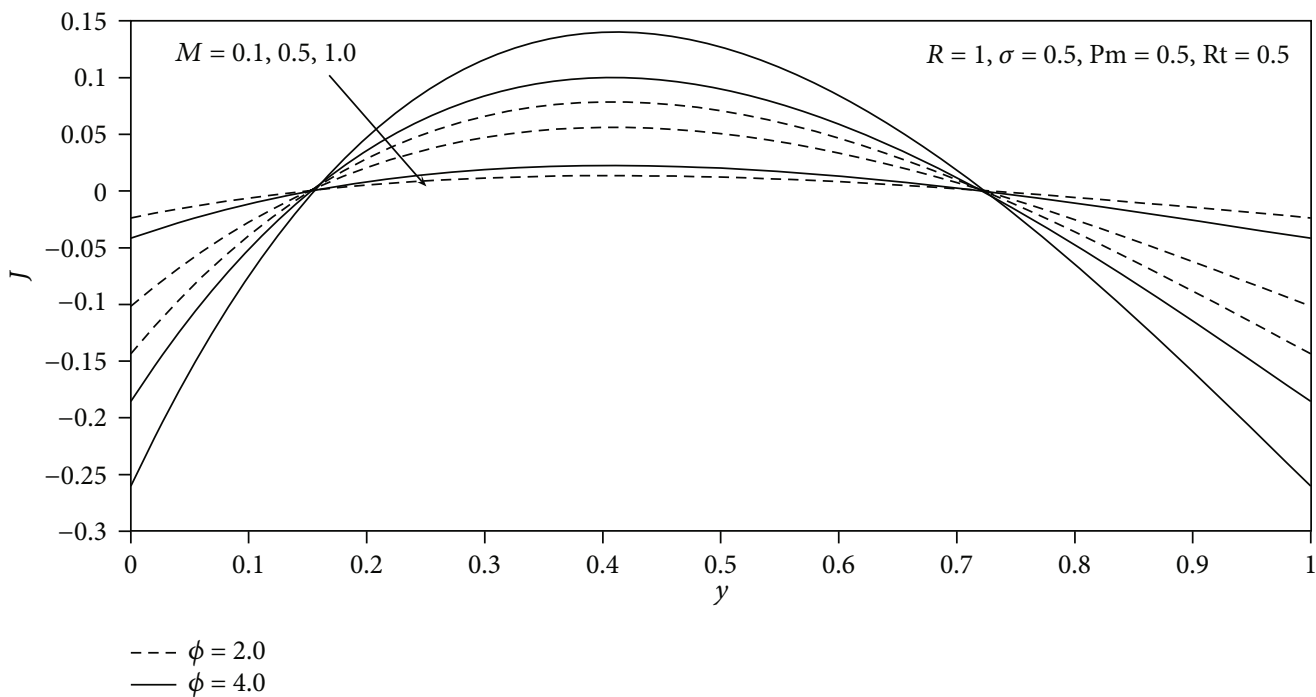

FIgURE 11: Induced current density for different values of $M$ and $\phi$.

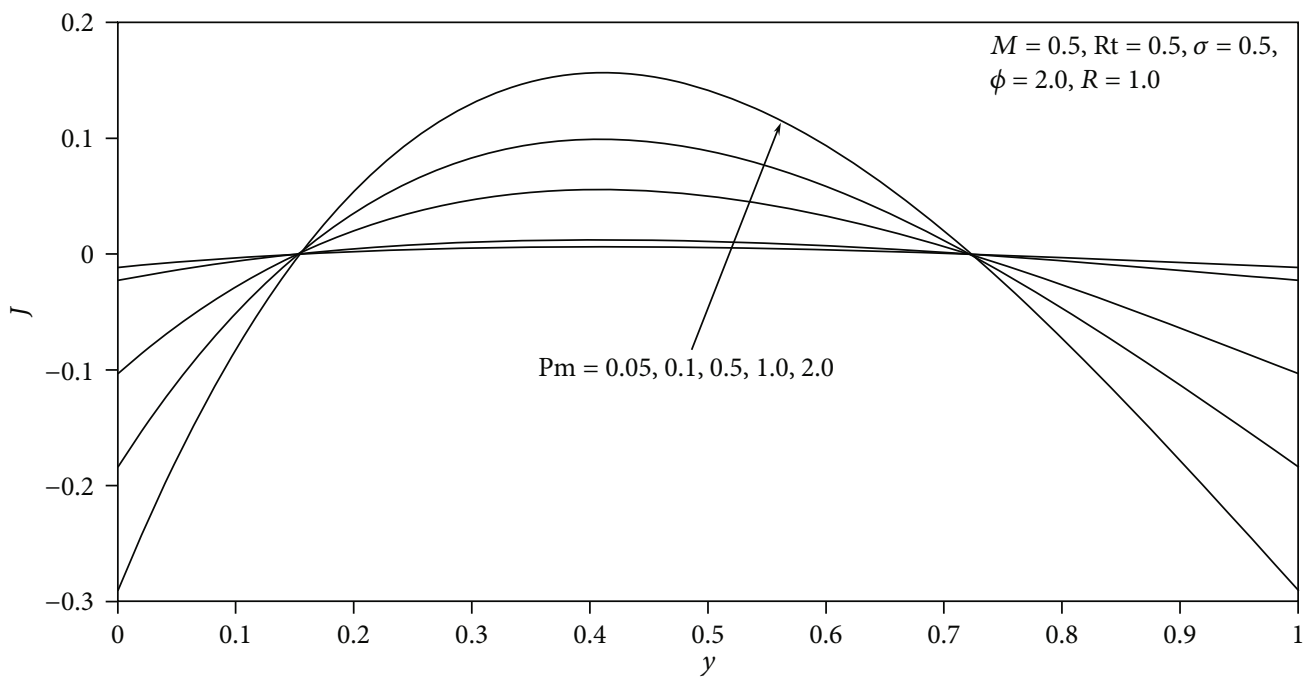

Figure 12: Induced current density for different values of the magnetic Prandtl number Pm.

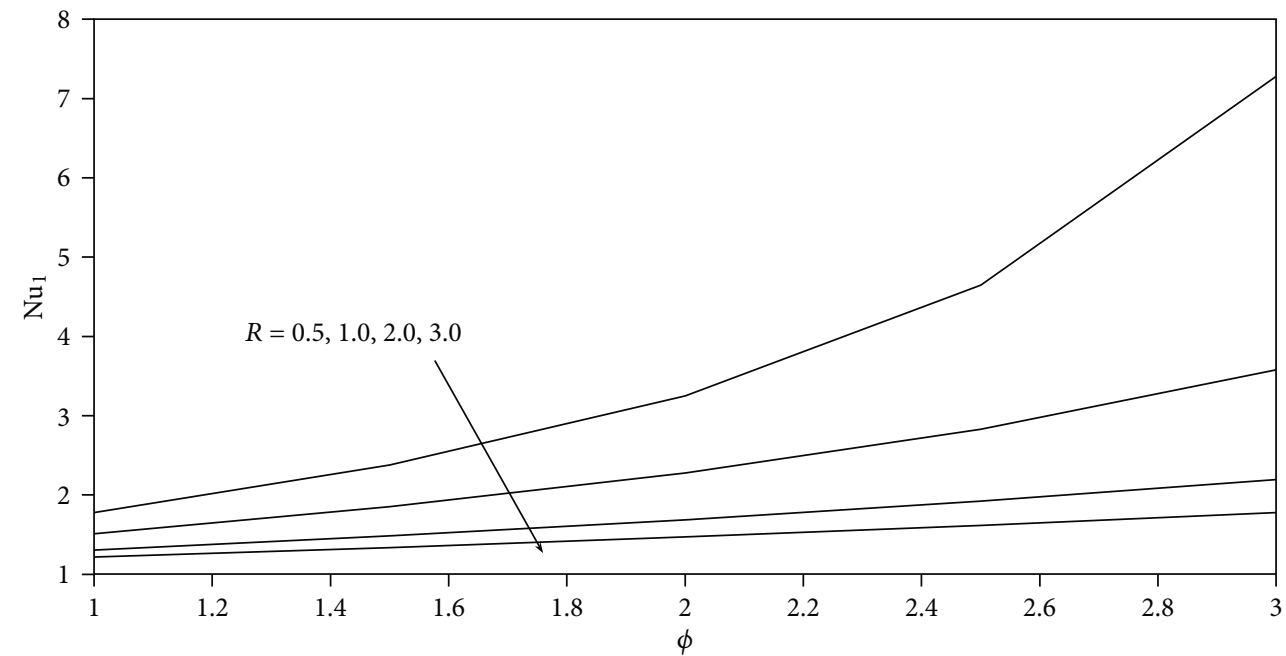

FIgURE 13: Variation of Nusselt number $\left(\mathrm{Nu}_{1}\right)$ versus $\phi$ for different values of $R$. 


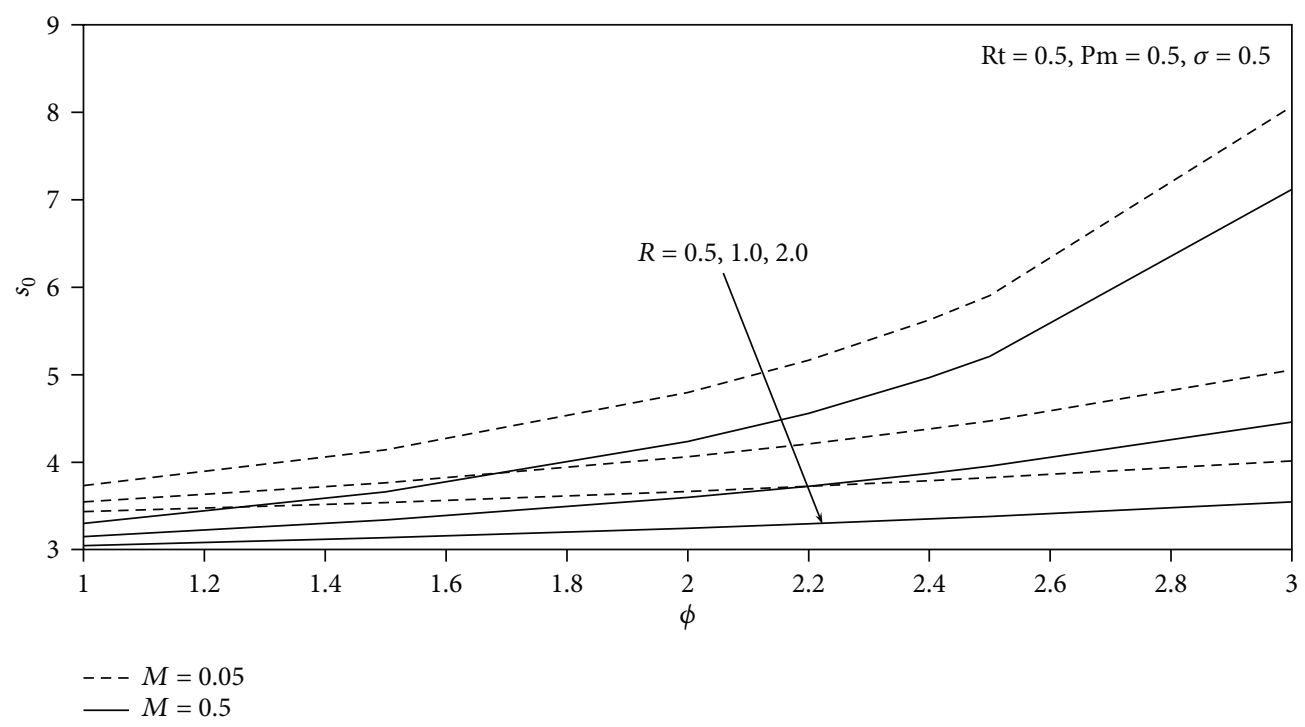

FIGURE 14: Variation of skin friction $\left(s_{0}\right)$ versus $\phi$ for different values of $M$ and $R$.

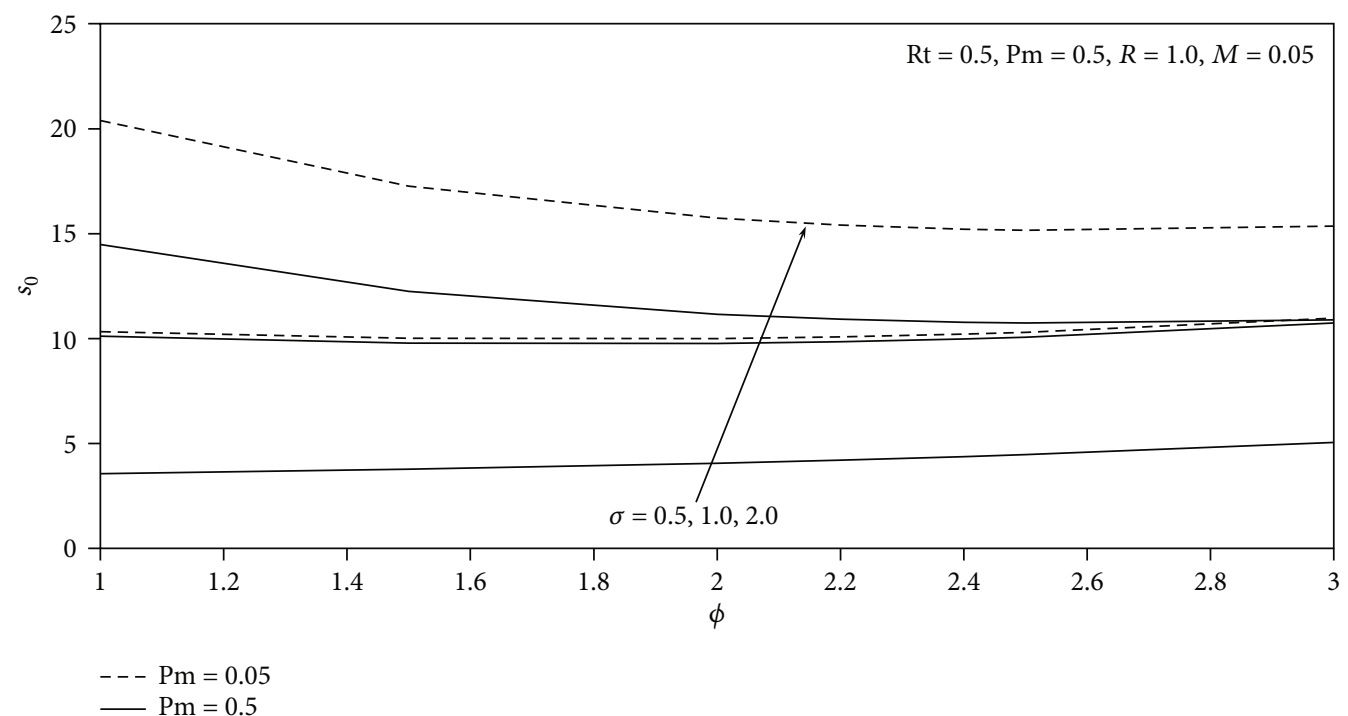

Figure 15: Variation of skin friction $\left(s_{0}\right)$ versus $\phi$ for different values of Pm and $\sigma$.

decreases with the increase in radiation parameter $R$ in the central part of the channel, while the reverse is the case near the channel walls. The influence of the Hartmann number $M$ and the heat generation coefficient $\phi$ on the induced current density is illustrated in Figure 11. The graph shows that the Hartmann number $M$ reduces the induced current density and the heat generation coefficient $\phi$ enhances the induced current density in the center of the channel, while the converse is the case near the walls. The impact of the magnetic Prandtl number Pm on the induced current density is shown in Figure 12. It is observed that the induced current density increases on the increase of the magnetic Prandtl number in the central region. It is also clear from Figures 10-12 that there exist two points of intersection inside the vertical channel where the induced current density is independent of the radiation parameter, Hartmann number, and Prandtl number.

Figure 13 demonstrates the effects of the radiation parameter $R$ and heat generation coefficient $\phi$ on the Nusselt number. It was noted that the heat flux at the right wall decreases with the increase of the radiation parameter $R$ while the heat flux at the left wall is constant. The effect of different parameters on skin friction is illustrated in Figures 14-17. It was observed that the magnitude of the skin friction on the isoflux channel wall decreases with the increase of the Hartmann number $M$, magnetic Prandtl number Pm, and radiation parameter $R$, whereas an increase in the value of the couple stress parameter $\sigma$ increases the skin friction (see Figures 14 and 15). The reverse is the case for the isothermal wall (see Figures 16 and 17). 


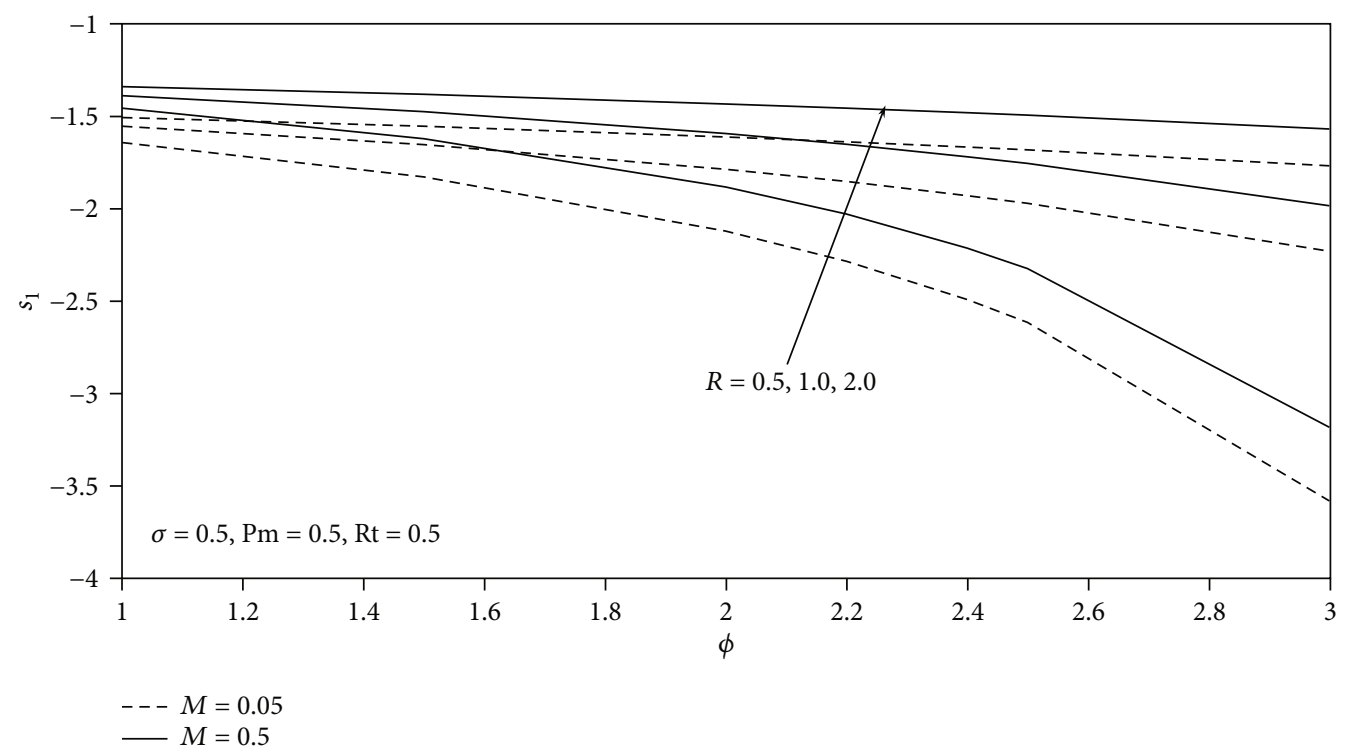

FiguRE 16: Variation of skin friction $\left(s_{1}\right)$ versus $\phi$ for different values of $M$ and $R$.

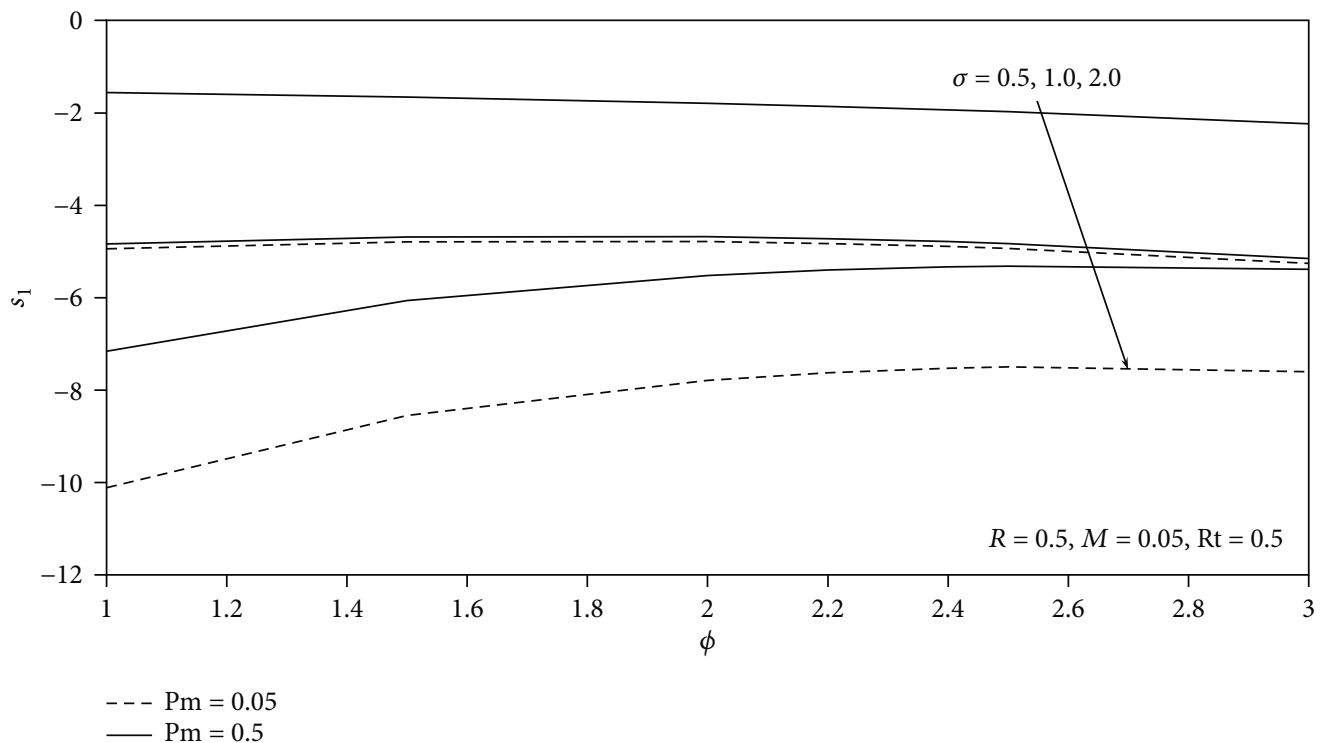

Figure 17: Variation of skin $\left(s_{1}\right)$ versus $\phi$ for different values of Pm and $\sigma$.

\section{Conclusion}

In the current analysis, the effect of thermal radiation, heat generation, and induced magnetic field on hydromagnetic free convection flow of couple stress fluid in an isoflux- isothermal vertical channel has been investigated. The governing equations are solved analytically, and closed form solutions are obtained. The outcomes of the present study are summarized as follows:

(1) The velocity of fluid particles decreases with the increase in the radiation parameter, Hartmann number, and magnetic Prandtl number. In contrast, the velocity profiles increase with an increase in the heat generation coefficient and couple stress parameter
(2) The induced magnetic field increases with the increase of the magnetic Prandtl number, Hartmann number, and heat generation coefficient and decreases with an increase of the radiation parameter within almost the left one-third of the channel, while the trend reverses itself near the isothermally heated wall

(3) It was observed that the increase in the magnetic Prandtl number and heat generation coefficient enhances the induced current density. In contrast, the radiation parameter and Hartmann number suppress the induced current density. The observations are for the middle part of the channel, whereas the opposite cases were observed near both walls 
(4) Temperature and rate of heat transfer increase with the increase in the heat generation parameter and have a decreasing tendency with the increase in radiation parameter

(5) It is also found that at the isoflux wall skin friction varies inversely with the parameters $R$ and $M$ on the increase in heat generation coefficient while the reverse is the case at the isothermal wall. The effect of the magnetic field on the skin friction is useful in mechanical engineering or modeling a system. We can easily optimize the value of skin friction by obtaining a suitable value of the Hartmann number

\section{Appendix}

$$
\begin{aligned}
c_{1} & =-\frac{1}{a_{1}}, c_{2}=\operatorname{Rt} \sec \left(a_{1}\right)-c_{1} \tan \left(a_{1}\right), c_{3}=\frac{b_{12}-c_{7} b_{11}}{b_{10}}, c_{5} \\
& =\frac{k_{2}-k_{1} c_{7} \sinh \left(a_{3}\right)}{b_{7}}, c_{7}=\frac{k_{8}}{k_{9}},
\end{aligned}
$$

$$
\begin{aligned}
c_{4} & =-c_{2} a_{4}\left(1+\frac{a_{1}^{2}}{a_{3}^{2}}\right)-c_{3}\left(1-\frac{a_{1}^{2}}{a_{3}^{2}}\right), c_{6}=\frac{c_{2} a_{4} a_{1}^{2}-c_{3} a_{2}^{2}}{a_{3}^{2}}, c_{8} \\
& =b_{8} c_{7}+b_{9}, a=1+\left(\frac{4 R}{3}\right), a_{1}=\sqrt{\frac{\phi}{a}},
\end{aligned}
$$

$$
\begin{aligned}
a_{2} & =\frac{1}{\sigma} \sqrt{\frac{1+\sqrt{1-4 M^{2} \sigma^{2} \mathrm{Pm}}}{2}}, a_{3}=\frac{1}{\sigma} \sqrt{\frac{1-\sqrt{1-4 M^{2} \sigma^{2} \mathrm{Pm}}}{2}}, a_{4} \\
& =\frac{1}{a^{2} a_{1}^{4}+a_{1}^{2}+M^{2} \mathrm{Pm}},
\end{aligned}
$$

$$
\begin{aligned}
b_{1}= & -c_{1} a_{4} \sin \left(a_{1}\right)-c_{2} a_{4} \cos \left(a_{1}\right), b_{2}=1-\cosh \left(a_{2}\right) \\
& +\left(\frac{a_{2}}{a_{3}}\right)\left\{\cosh \left(a_{2}\right)-\cosh \left(a_{3}\right)\right\},
\end{aligned}
$$$$
b_{3}=b_{1}+c_{2} a_{4} \cosh \left(a_{2}\right)
$$$$
+\left(\frac{c_{2} a_{4} a_{1}^{2}}{a_{3}}\right)\left\{\cosh \left(a_{2}\right)-\cosh \left(a_{3}\right)\right\}, b_{4}=-a_{1}^{2} b_{1} \text {, }
$$

$$
\begin{gathered}
b_{5}=a_{2}^{2}\left\{\cosh \left(a_{2}\right)-\cosh \left(a_{3}\right)\right\}-\left(\frac{a_{2}^{4}}{a_{3}^{2}}\right) \cosh \left(a_{2}\right), \\
b_{6}=b_{4}+c_{2} a_{4}\left\{a_{2}^{2} \cosh \left(a_{2}\right)-a_{1}^{2} \cosh \left(a_{3}\right)\right\} \\
+c_{2} a_{4} a_{1}^{2}\left(\frac{a_{2}}{a_{3}}\right)^{2} \cosh \left(a_{2}\right),
\end{gathered}
$$

$$
\begin{aligned}
b_{7}= & \left(b_{5}+b_{2} a_{2}^{2}\right) \sinh \left(a_{2}\right), b_{8}=\left(\frac{M P m}{a_{3}}\right) \\
& +\left(\frac{M P m}{a_{2} b_{7}}\right) k_{1} \sinh \left(a_{3}\right), b_{9}=M P m\left(\frac{k_{2}}{a_{2} b_{7}}-\frac{a_{4} c_{1}}{a_{1}}\right),
\end{aligned}
$$

$$
\begin{aligned}
b_{10} & =\frac{M P m}{a_{2} a_{3}^{2}}\left\{a_{3}^{2} \sinh \left(a_{2}\right)-a_{2} a_{3} \sinh \left(a_{2}\right)+a_{2} \sinh \left(a_{3}\right)\right\}, b_{11} \\
& =b_{8}+M \operatorname{MPm} k_{7},
\end{aligned}
$$

$$
\begin{aligned}
b_{12} & =-b_{9}+k_{6}+\operatorname{MPm}\left(c_{2} k_{3}+k_{4}-k_{5}\right), b_{13} \\
& =\sinh \left(a_{3}\right)-\frac{b_{2} b_{11}}{b_{10}}, b_{14}=b_{3}-\frac{b_{2} b_{12}}{b_{10}},
\end{aligned}
$$

$$
\begin{aligned}
k_{1} & =b_{5}+b_{3} a_{3}^{2}, k_{2}=b_{3} b_{5}+b_{2} b_{6}, k_{3}=\frac{a_{4} a_{1} \sinh \left(a_{3}\right)}{a_{3}^{2}}, k_{4} \\
& =\frac{k_{2} \cosh \left(a_{2}\right)}{a_{2} b_{7}}, k_{5}=\frac{c_{2} a_{4} \sinh \left(a_{2}\right)\left(1+a_{1}^{2} / a_{3}^{2}\right)}{a_{2}},
\end{aligned}
$$

$$
\begin{aligned}
k_{6} & =\left(\frac{M \operatorname{Pm} a_{4}}{a_{1}}\right)\left\{c_{2} \sin \left(a_{1}\right)-c_{1} \cos \left(a_{1}\right)\right\}, k_{7} \\
& =\frac{k_{1} \sinh \left(a_{3}\right) \cosh \left(a_{2}\right)}{a_{2} b_{7}}-\frac{\cosh \left(a_{2}\right)}{a_{3}},
\end{aligned}
$$

$k_{8}=b_{7} b_{14}-k_{2} \sinh \left(a_{2}\right), k_{9}=b_{7} b_{13}-k_{1} \sinh \left(a_{2}\right) \sinh \left(a_{3}\right)$.

\section{Nomenclature}

$h: \quad$ Channel width

M: Hartmann number

$B_{0}^{\prime}$ : $\quad$ Constant strength of applied magnetic field

$B_{x}^{\prime}$ : Dimensional induced magnetic field

$B: \quad$ Dimensionless induced magnetic field

$J: \quad$ Induced current density

$u^{\prime}$ : $\quad$ Dimensional velocity

$u$ : Dimensionless velocity

$T: \quad$ Temperature of fluid

$T_{1}, T_{2}$ : Prescribed boundary temperatures

$\mu$ : $\quad$ Dynamic viscosity

$v$ : $\quad$ Kinematic viscosity

$\theta: \quad$ Dimensionless temperature

Rt: $\quad\left(T_{2}-T_{1}\right) / \Delta T$, temperature difference ratio

$\eta$ : $\quad$ Couple stress viscosity

g: Acceleration due to gravity

$c_{p}$ : Specific heat at constant pressure

$T_{0}$ : $\quad$ Reference temperature

$Q_{0}$ : Heat generation coefficient

$x^{\prime}, y^{\prime}$ : Space coordinates

$\mu_{e}: \quad$ Magnetic permeability

$\beta$ : $\quad$ Thermal expansion coefficient

$\sigma_{e}: \quad$ Fluid electrical conductivity

$\rho: \quad$ Fluid density

R: $\quad$ Radiation parameter 
$u_{0}: \quad$ Reference velocity

$\Delta T: \quad$ Reference temperature difference

Pm: Magnetic Prandtl number

$\phi$ : $\quad$ Heat generation coefficient.

\section{Data Availability}

The data used to support the finding of this study is included with in the article.

\section{Conflicts of Interest}

The authors declare that they have no competing interests.

\section{References}

[1] E. M. Sparrow and R. D. Cess, "The effect of a magnetic field on free convection heat transfer," International Journal of Heat and Mass Transfer, vol. 3, no. 4, pp. 267-274, 1961.

[2] G. Poots, "Laminar natural convection flow in magnetohydrodynamics," International Journal of Heat and Mass Transfer, vol. 3, no. 1, pp. 1-25, 1961.

[3] S. K. Ghosh, O. Anwar Bég, and J. Zueco, "Hydromagnetic free convection flow with induced magnetic field effects," Meccanica, vol. 45, no. 2, pp. 175-185, 2010.

[4] R. K. Singh, A. K. Singh, N. C. Sacheti, and P. Chandran, "On hydromagnetic free convection in the presence of induced magnetic field," Heat and Mass Transfer, vol. 46, no. 5, pp. 523-529, 2010.

[5] Sarvesanand and A. K. Singh, "Magnetohydrodynamic free convection between vertical parallel porous plates in the presence of induced magnetic field," Springer Plus, vol. 4, no. 1, p. 333, 2015.

[6] H. N. Zaidi and N. Ahmad, "MHD convection fluid flow and heat transfer in an inclined microchannel with heat generation," American Journal of Applied Mathematics, vol. 5, no. 5, pp. 124-131, 2017.

[7] A. Kumar and A. K. Singh, "Unsteady MHD free convective flow past a semi-infinite vertical wall with induced magnetic field," Applied Mathematics and Computation, vol. 222, pp. 462-471, 2013.

[8] B. K. Jha and B. Aina, "Role of induced magnetic field on MHD natural convection flow in vertical microchannel formed by two electrically non-conducting infinite vertical parallel plates," Alexandria Engineering Journal, vol. 55, no. 3, pp. 2087-2097, 2016.

[9] B. K. Jha and B. Aina, "Magnetohydrodynamic natural convection flow in a vertical micro-porous-channel in the presence of induced magnetic field," Communications in Nonlinear Science and Numerical Simulation, vol. 64, pp. 14-34, 2018.

[10] R. Mohammad, M. I. Khan, N. B. Khan, and M. Jameel, "Magnetohydrodynamics (MHD) radiated nanomaterial viscous material flow by a curved surface with second order slip and entropy generation," Computer Methods and Programs in Biomedicine, vol. 189, article 105294, 2020.

[11] R. D. Cess, "The interaction of thermal radiation with free convection heat transfer," International Journal of Heat and Mass Transfer, vol. 9, no. 11, pp. 1269-1277, 1966.

[12] H. Bouali and A. Mezrhab, "Combined radiative and convective heat transfer in a divided channel," International Journal of Numerical Methods for Heat \& Fluid Flow, vol. 16, no. 1, pp. 84-106, 2006.

[13] T. Grosan and I. Pop, "Thermal radiation effect on fully develop mixed convection flow in a vertical channel," Technische Mechanik, vol. 27, no. 1, pp. 37-47, 2007.

[14] K. Kaladhar, S. S. Motsa, and D. Srinivasacharya, "Mixed convection flow of couple stress fluid in a vertical channel with radiation and soret effects," Journal of Applied Fluid Mechanics, vol. 9, no. 1, pp. 43-50, 2016.

[15] M. Rashid, M. I. Khan, T. Hayat, M. I. Khan, and A. Alsaedi, "Entropy generation in flow of ferromagnetic liquid with nonlinear radiation and slip condition," Journal of Molecular Liquids, vol. 276, pp. 441-452, 2019.

[16] B. J. Gireesha, G. Sowmya, M. I. Khan, and H. F. Öztop, "Flow of hybrid nanofluid across a permeable longitudinal moving fin along with thermal radiation and natural convection," Computer Method and Programs in Biomedicine, vol. 185, pp. 105166-105166, 2020.

[17] V. K. Stokes, "Couple stresses in fluids," The Physics of Fluids, vol. 9, no. 9, pp. 1709-1715, 1966.

[18] V. K. Stokes, "Effects of couple stresses in fluids on hydromagnetic channel flows," The Physics of Fluids, vol. 11, no. 5, pp. 1131-1133, 1968.

[19] V. M. Soundalgekar and R. N. Aranake, "Effects of couple stresses in MHD channel flow," Nuclear Engineering and Design, vol. 44, no. 3, pp. 301-308, 1977.

[20] J. C. Umavathi, M. S. Malashetty, A. J. Chamkha, and A. Al Mudhaf, Free Convection Flow of a Couple Stress Fluid in a Vertical Channel, International Mechanical Engineering conference, Kuwait, 2004.

[21] K. Kaladhar, "Natural convection flow of couple stress fluid in a vertical channel with hall and joule heating effects," Procedia Engineering, vol. 127, pp. 1071-1078, 2015.

[22] O. D. Makinde and A. S. Eegunjobi, "MHD couple stress nanofluid flow in a permeable wall channel with entropy generation and nonlinear radiative heat," Journal of Thermal Science and Technology, vol. 12, no. 2, 2017. 